\title{
Inkjet-Printed Interdigital Bandpass Filter with Wide Stopband Using Multilayer Liquid Crystal Polymer Technique
}

\author{
Li-Chun Chang, ${ }^{1,2}$ Cheng-Lin Cho $\mathbb{D}^{3}{ }^{3}$ Sameer Kamrudin Bachani $\mathbb{D}^{4}{ }^{4}$ \\ and Hsuan-Ling Kao iD ${ }^{5,6}$ \\ ${ }^{1}$ Department of Materials Engineering, Ming Chi University of Technology, 84 Gongzhuan Rd., Taishan Dist., \\ New Taipei City 24301, Taiwan \\ ${ }^{2}$ Center for Thin Film Technologies and Applications, Ming Chi University of Technology, New Taipei City, Taiwan \\ ${ }^{3}$ Department of Engineering and System Science, National Tsing Hua University, No. 101, Section 2, Kuang-Fu Road, \\ Hsin-Chu, Taiwan \\ ${ }^{4}$ Department of Mechanical Engineering, National Taiwan University of Science and Technology, No. 43, Keelung Rd., Sec. 4, \\ Taipei 10607, Taiwan \\ ${ }^{5}$ Department of Electronic Engineering, Chang Gung University, 259 Wen-Hwa 1st Rd., Kwei-Shan, Taoyuan, Taiwan \\ ${ }^{6}$ Department of Dermatology, Chang Gung Memorial Hospital, Linkou Branches, Kwei-Shan Tao-Yuan, Taiwan
}

Correspondence should be addressed to Hsuan-Ling Kao; snoopy@mail.cgu.edu.tw

Received 10 February 2018; Revised 21 April 2018; Accepted 30 April 2018; Published 15 May 2018

Academic Editor: N. Nasimuddin

Copyright $\odot 2018$ Li-Chun Chang et al. This is an open access article distributed under the Creative Commons Attribution License, which permits unrestricted use, distribution, and reproduction in any medium, provided the original work is properly cited.

This article presents a two-layer inkjet-printed interdigital bandpass filter using lamination bonding process on liquid crystal polymer (LCP) substrates for radio frequency electronic applications. Various percentages of torque force were applied over a $4 \times 4 \mathrm{~cm}^{2}$ area with a $942 \mathrm{~kg}$ fixed force in the lamination bonding process. The insertion loss and surface morphology of the inkjet-printed silver film were examined on various torque forces to develop the lamination bonding process. The lamination bonding was performed at $12 \%$ torque and $270^{\circ} \mathrm{C}$. A three-dimensional bandpass filter was realized with a $\mathrm{S}_{21}$ of $-2.2 \mathrm{~dB}$ at $11.5 \mathrm{GHz}$ with a $17 \%$ fractional bandwidth. A multilayer inkjet-printed bandpass filter was successfully developed to verify the design methodology and fabrication of inkjet-printing technology and lamination bonding technique for a three-dimensional integrated circuit package.

\section{Introduction}

Three-dimensional (3D) technologies [1-3] provide more designs and compact sizes for radio frequency (RF) and millimeter wave devices. Low-temperature cofired ceramic (LTCC) packaging method is useful for microwave applications because of excellent physical and electrical properties [3-5]. However, the sintering temperature of LTCC should be at the level of $850^{\circ} \mathrm{C}$. Compared to printed circuit board, the cost of LTCC is expensive. Recently, liquid crystal polymers (LCPs) have become a favorable material for RF applications because of an impressive loss tangent, lower thermal expansion coefficient, and lower moisture absorption. Additionally, the dielectric constant of LCP is 2.9 , which is lower than that of LTCC $[6,7]$ and is favorable for multilayer lamination because it provides more tolerances for registration error. Several authors have presented studies on the ultrawideband bandpass filter using multilayer LCP technology at different frequencies $[6,8]$. Multilayer inductors and capacitors using LCP technology have been demonstrated for high-pass filter design $[7,9]$. A low-loss integrated waveguide bandpass filter using LCP substrate was published to provide an inexpensive low-loss hermetic packaging solution [10]. No losses were recorded over a frequency range of $25 \mathrm{GHz}$ and $15 \mathrm{GHz}$ for coplanar waveguide (CPW), and microstrip via transitions were examined, respectively [11]. Therefore, multilayer LCP technologies are suitable for RF applications.

Inkjet printing technology has gained popularity because of its cost-effective direct-write technology and being environmentally friendly. Several studies on the implementation and characterization of inkjet-printed silver film on an LCP substrate have been conducted $[12,13]$. In our study, the 


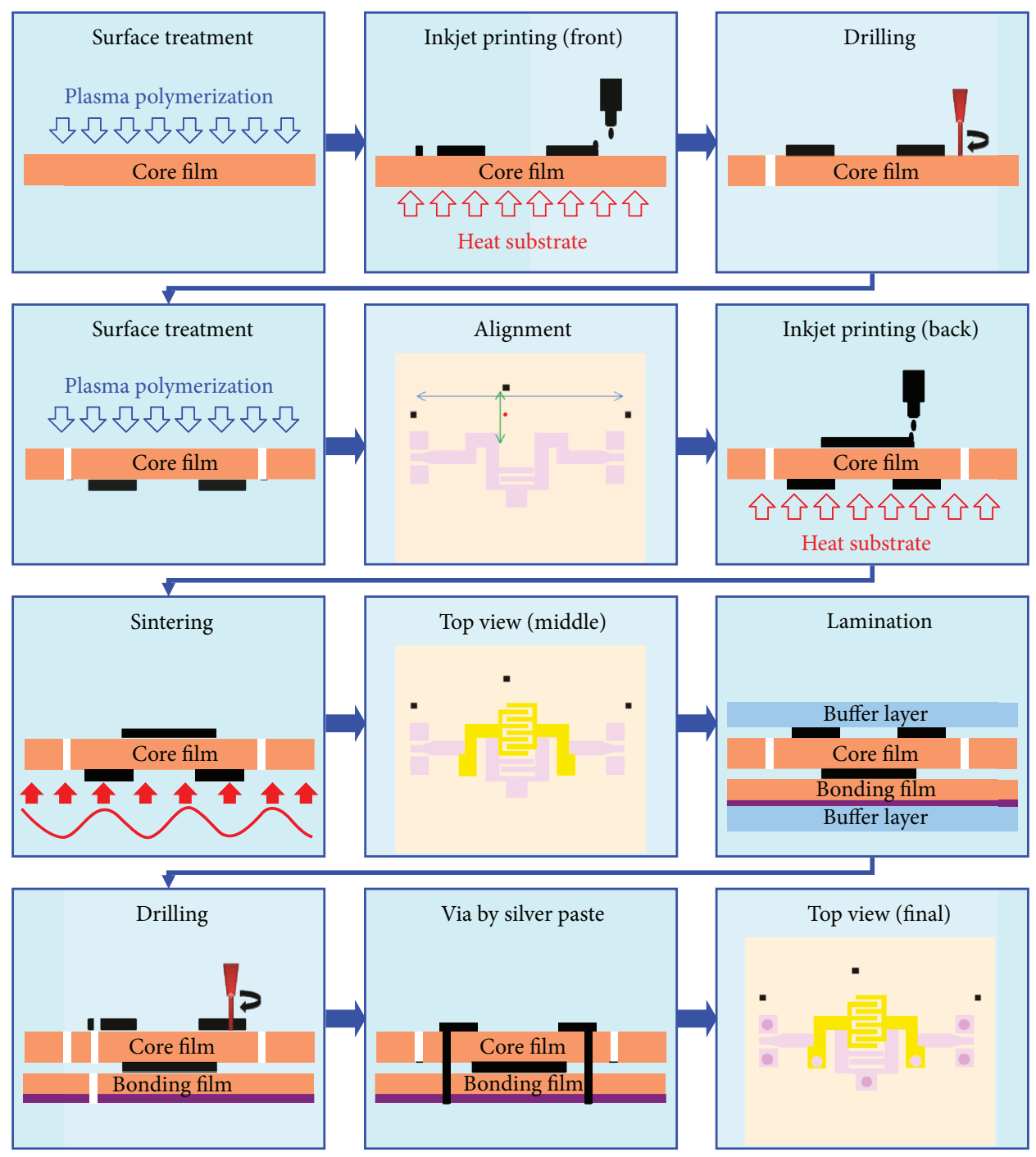

FIGURE 1: Inkjet printing and lamination bonding process flow.

multilayer LCP technology was utilized at high torque forces and a high temperature. The strength of the inkjet-printed silver film at various torque forces was studied. According to the strength results, a multilayer inkjet-printed interdigital bandpass filter was realized to demonstrate a high performance and cost-effective integration circuit for electronic package applications. This paper is organized as follows. Section 2 describes the processes for fabricating the inkjetprinted silver film and the lamination bonding process for multilayer LCP substrates. Section 3.1 focuses on the insertion loss and surface morphology of inkjet-printed silver film under various torque forces. Section 3.2 describes the structure and fabrication of the multilayer bandpass filter. In Section 4, we provide the conclusions.

\section{Fabrication Process}

Figure 1 illustrates the process flow of inkjet printing and lamination bonding for three-dimensional interdigital bandpass filter. DGP-40LT-15C silver ink was used to print the metal layers using a DMP-2800 inkjet printer. Two types of Rogers LCP substrates including ULTRALM 3850 (core film) and 3908 bondply (bonding film) were adopted which have similar thermal expansion and dielectric constants [14]. The steps for fabricating the inkjet-printed threedimensional interdigital bandpass filter are as follows:

(1) Plasma polymerization process was applied at $3 \mathrm{~W}$, $5 \mathrm{~s}$ for surface treatment.

(2) Ten-pass silver ink was printed at $60^{\circ} \mathrm{C}$ onto the front of the core.

(3) Three vias were drilled in the core film for subsequent alignment.

(4) The LCP was flipped to layer 2 and treated by plasma polymerization.

(5) Layer 2 was aligned using the horizontal vias, and then the intersected vertical via was the starting point for layer 2 printing.

(6) The backside of the silver film was printed. 


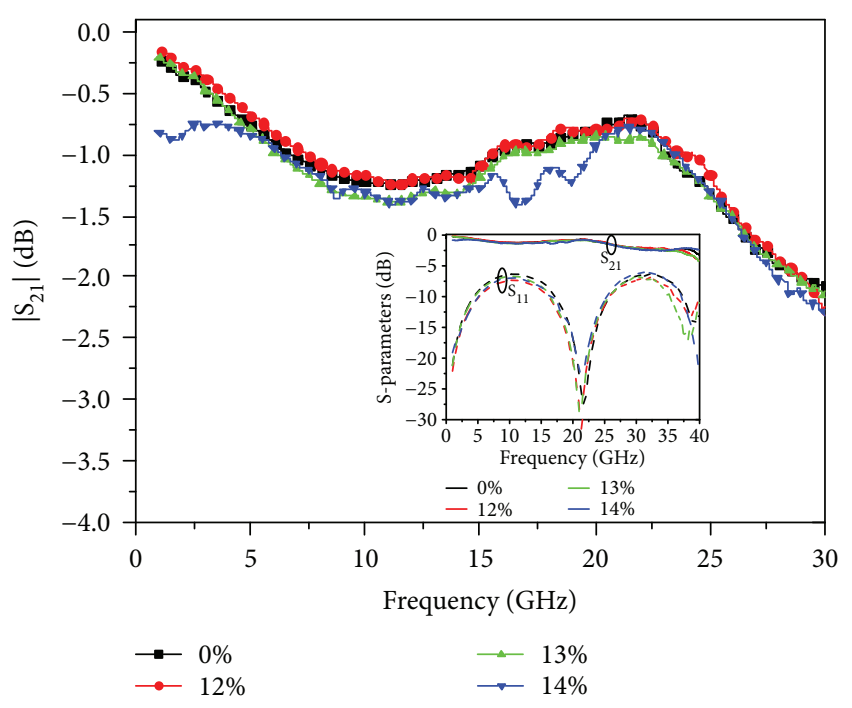

FIGURE 2: Insertion loss and S-parameters (inserted figure) of silver lines at various torque forces.

(7) The double-sided silver films were subjected to $270^{\circ} \mathrm{C}$ for $1 \mathrm{~h}$.

(8) A two-layer inkjet-printed silver film was achieved.

(9) The core film and a copper ground film were laminated using a bonding film at various torques and $270^{\circ} \mathrm{C}$, throughout which its properties were studied. The sample was protected at the top and bottom by two buffer layers.

(10) Eight ground vias were drilled using a drilling machine with a $0.2 \mathrm{~mm}$ diameter needle.

(11) The eight vias were filled with a conductive paste to connect the background plane.

(12) Fabrication of the inkjet-printed bandpass filter by lamination bonding was finished.

\section{Results and Discussion}

3.1. Various Lamination Bonding Percentages. The lamination bonding process was applied at a constant pressure from $25^{\circ} \mathrm{C}$ to $270^{\circ} \mathrm{C}$, and the temperature was cooled down to room temperature. Various percentages of torque force were tuned over a $4 \times 4 \mathrm{~cm}^{2}$ area with a $942 \mathrm{~kg}$ fixed force. The sample was clearly open while the torque force was smaller than $12 \%$. An obvious crack was observed at $15 \%$ torque force. Therefore, the samples were measured at torque force of 12 to $14 \%$. Figure 2 shows the changes in the insertion losses of the printed line (width, $100 \mu \mathrm{m}$; length, $4000 \mu \mathrm{m}$ ) and a probing pad on a $100 \mu \mathrm{m}$ LCP substrate during several torque force experiments. The inserted figure shows the Sparameters of the silver line, and the resonant frequency of the printed line was approximately $22 \mathrm{GHz}$. The insertion loss at the resonant frequency was dependent on the torque force. The insertion loss at $12 \%(<0.68 \mathrm{~dB}$ at $22 \mathrm{GHz})$ was comparable to that of the $0 \%$ sample. The insertion losses at the resonant frequency below the $12 \%$ printed line were 0.22 and $0.09 \mathrm{~dB}$ when torque forces were $13 \%$ and $14 \%$, respectively. However, the average degradations in the value of insertion losses over a whole frequency range were -1 and $-1.9 \mathrm{~dB}$ at $13 \%$ and $14 \%$, respectively. Figure 3 shows the surface morphologies at various torque forces. The surface roughness of the silver film increased with torque force. No crack was observed at a torque force of $0 \%$ and $12 \%$. At $13 \%$, few cracks were found occasionally on the surface of the silver film. A lot of surface cracks were generated in the microstructure images while bonding at $14 \%$. The surface morphology was consistent with the $S_{21}$ value. Therefore, $12 \%$ was the optimal torque force for the lamination bonding process.

3.2. Multilayer Inkjet-Printed Bandpass Filter. Figure 4 illustrates the interdigital bandpass filter comprising two LCP layers and three metal layers. The bandpass filter comprises two feeding lines on layer 1 , two quarterwavelength resonators on layer 2 , and a ground on layer 3 for the transmission lines on the other layers. The feeding lines provided a broadside coupling to the resonators on layer 2. At the other end of the feeding lines, the ground vias were connected to generate three transmission zeros (TZs) because of the inductive source-load coupling [15]. Two resonators were meandered on layer 2 and coupled with each other using an interdigital capacitor. The bandpass filter was simulated using electromagnetic simulation software. The proposed filter was designed with the following parameters: a permittivity $\left(\varepsilon_{\mathrm{r}}\right)$ of 2.9 and a loss tangent $(\tan \delta)$ of 0.0025 for LCP substrate and a conductivity of $1 \times 10^{7} \mathrm{~S} / \mathrm{m}$ and a thickness of $3.4 \mu \mathrm{m}$ for silver film. Figure 5 shows the simulated transmission characteristic of the layout for various spaces of inductive sourceload coupling $\left(\mathrm{S}_{1}\right)$. No transmission zero was produced without inductive source-load coupling, and the strength of broadside coupling was weak. With inductive sourceload coupling $\left(\mathrm{S}_{1}=0.3 \mathrm{~mm}\right)$, two transmission zeros $\left(\mathrm{TZ}_{1}\right.$ and $\mathrm{TZ}_{2}$ ) near the passband were produced because of the cross coupling between feeding lines. Additionally, transmission zero $\left(\mathrm{TZ}_{3}\right)$ at stopband is generated while $\mathrm{S}_{1} \leqq 0.2 \mathrm{~mm}$ because the two transmission paths for the signals (source-load path and source-resonator 1-resonator 2load path) have the same magnitudes but are out of phase. The transmission zeros can be tuned by $S_{1}$ because the strength of the source-load coupling is changed. This also verifies that the three transmission zeros were generated by the inductive source-load coupling. Figure 6 shows the frequency responses of various finger numbers (nr) for interdigital capacitor. The interdigital capacitor shortened the length of the coupling region, and the resonant frequency was tuned by adjusting the capacitance. The coupling ratio $(k)$ between two resonators affected the insertion loss. Figure 7 shows the extracted coupling ratio at $f_{0}$ against $\mathrm{L}_{13}$ and $\mathrm{S}_{2}$. From the resonant frequency and the required $k$, the size of the interdigital capacitor was determined. Figure 8 shows the three TZ positions relative to the various couple length of two feeding lines $\left(\mathrm{L}_{7}\right)$. The $\mathrm{TZ}_{3}$ can be tuned 


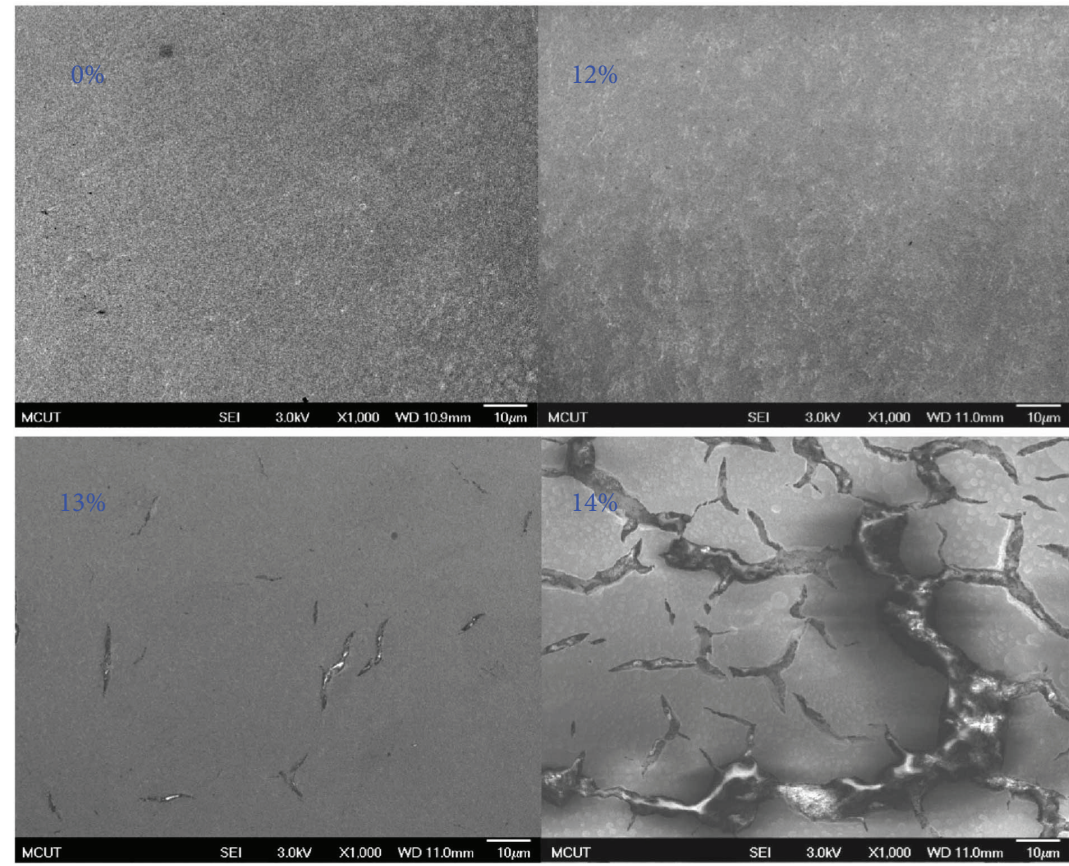

FIGURE 3: Surface morphology of silver film at various torque forces.

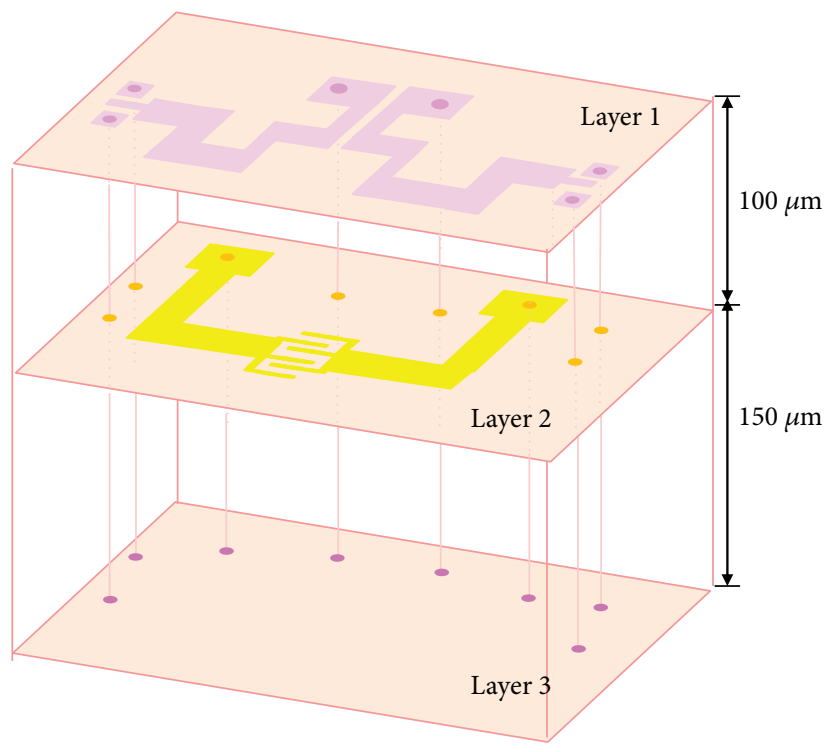

(a)

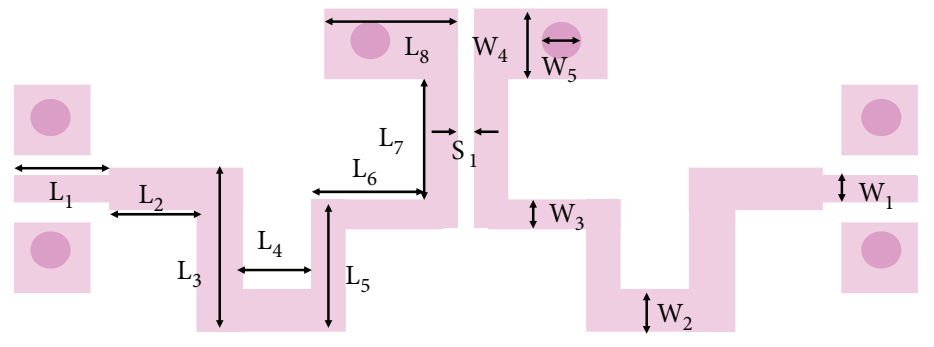

(b)

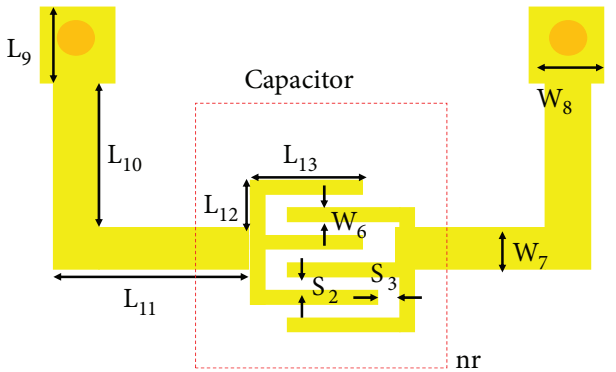

(c)

FIGURE 4: Structure and photograph of proposed bandpass filter. 


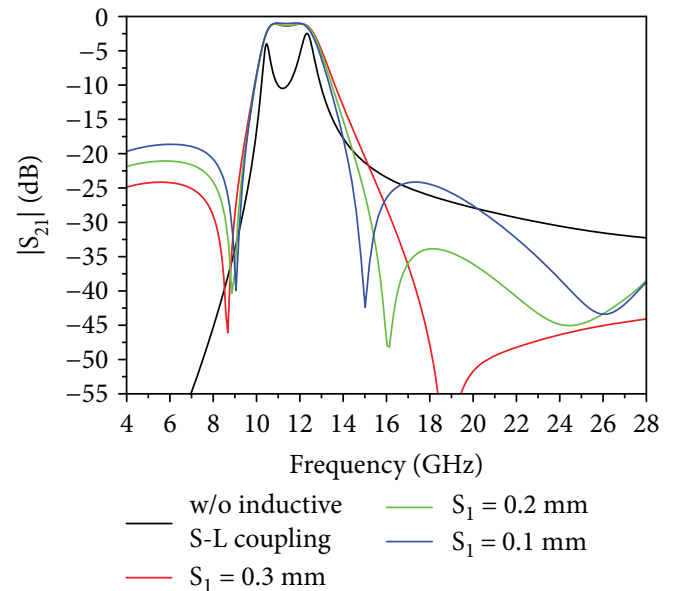

FIGURE 5: Simulated frequency responses without inductive source-load coupling and with inductive source-load coupling at various $S_{1}$.

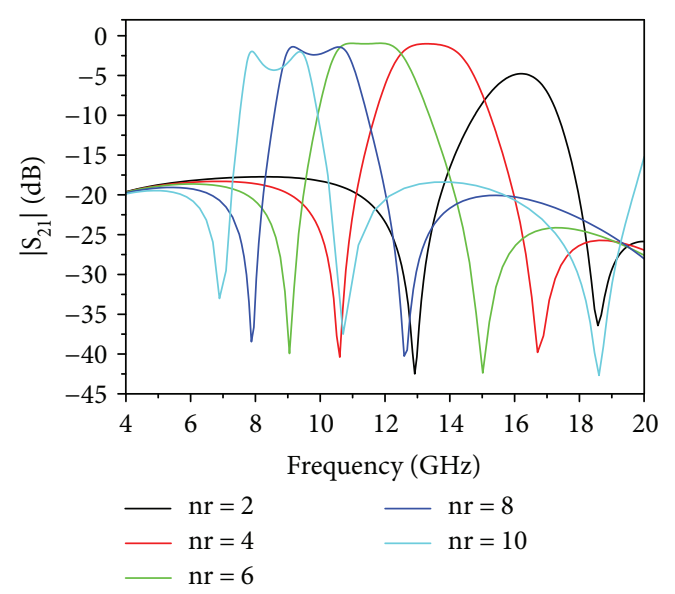

FIgURE 6: Simulated frequency responses for the finger number of interdigital capacitor.

by adjusting the coupling length between two feeding lines on layer 1 to improve the skirt selectivity and to enhance stopband while the $\mathrm{TZ}_{1}$ and $\mathrm{TZ}_{2}$ remain fixed. The $\mathrm{TZ}_{3}$ was saturated at $28.7 \mathrm{GHz}$, while $\mathrm{L}_{7}$ was $0.95 \mathrm{~mm}$. Considering a wide stopband and compact size, we selected $\mathrm{L}_{7}$ as $1.15 \mathrm{~mm}$. Based on the required responses, the parameters are determined as follows: $\mathrm{L}_{1}=0.7, \mathrm{~L}_{2}=0.3, \mathrm{~L}_{3}=1.18, \mathrm{~L}_{4}=$ $0.3, \mathrm{~L}_{5}=1.05, \mathrm{~L}_{6}=0.79, \mathrm{~L}_{7}=1.15, \mathrm{~L}_{8}=0.8, \mathrm{~L}_{9}=0.7, \mathrm{~L}_{10}=$ $0.88, \mathrm{~L}_{11}=1, \mathrm{~L}_{12}=0.45, \mathrm{~L}_{13}=1, \mathrm{~W}_{1}=0.07, \mathrm{~W}_{2}=0.3, \mathrm{~W}_{3}=$ $0.2, \mathrm{~W}_{4}=0.4, \mathrm{~W}_{5}=0.3, \mathrm{~W}_{6}=0.12, \mathrm{~W}_{7}=0.3, \mathrm{~W}_{8}=0.6$, $\mathrm{S}_{1}=0.1, \mathrm{~S}_{2}=0.15, \mathrm{~S}_{3}=0.2(\mathrm{~mm})$, and $\mathrm{nr}=4$. These prototypes occupied an LCP area of $5.28 \times 3.32 \times 0.25 \mathrm{~mm}^{3}$ $\left(0.32 \lambda_{\mathrm{g}} \times 0.2 \lambda_{\mathrm{g}} \times 0.015 \lambda_{\mathrm{g}}\right)$ including probing pads.

Figures $9(a)$ and $9(\mathrm{~b})$ show the photographs of the bandpass filter on layer 1 and layer 2 , respectively. With $20 \mu \mathrm{m}$ drop spacing and $30 \mu \mathrm{m}$ droplet size, the resolution of inkjet-printed film resolution was $50 \mu \mathrm{m}$. The registration error is approximately $50 \mu \mathrm{m}$ because the diameter of alignment is $100 \mu \mathrm{m}$. The registration error was approximately

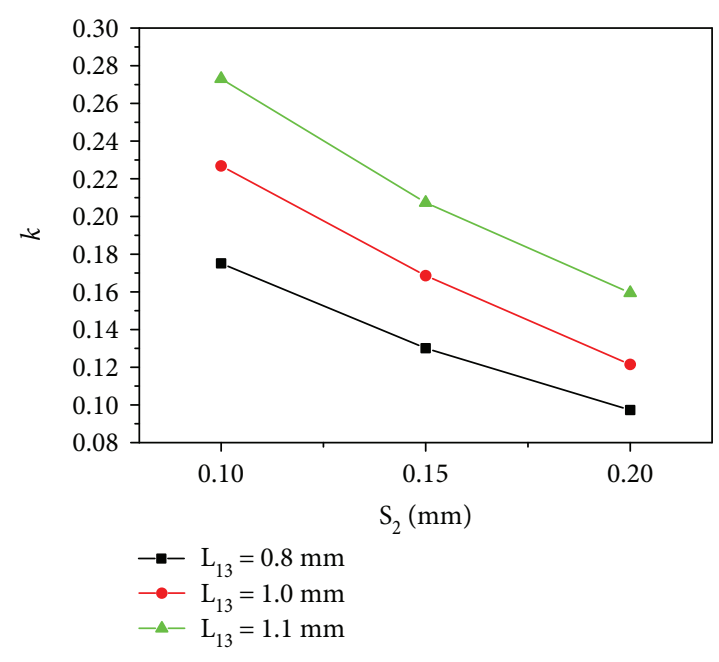

FIgURE 7: Coupling ratio with the value of $S_{2}$ and $L_{13}$.

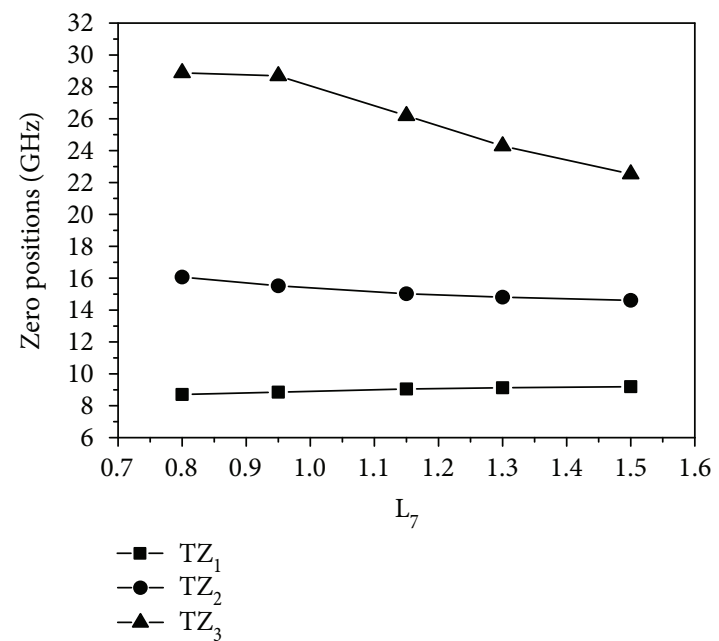

FIgURE 8: Three transmission zeros versus $\mathrm{L}_{7}$.

$50 \mu \mathrm{m}$ because the diameter of alignment was $100 \mu \mathrm{m}$. Figure 9(c) compares the simulated and measured Sparameters of the proposed bandpass filter. The measured maximal $\mathrm{S}_{21}$ of $2.24 \mathrm{~dB}$ at $11.4 \mathrm{GHz}$ and the $\mathrm{S}_{11}$ was larger than the $12 \mathrm{~dB}$ in the passband. $\mathrm{A} 3 \mathrm{~dB}$ passband was centered at $11.5 \mathrm{GHz}$ with a fractional bandwidth of $17 \%$. The three transmission zeros located at $8.5,17.5$, and $26.5 \mathrm{GHz}$ provided high skirt selectivity and enhanced rejection levels. The stopband rejection is more than $24 \mathrm{~dB}$ up to $31 \mathrm{GHz}$. Note that the transmission zero at $20 \mathrm{GHz}$ is due to the high resistance of drilled vias. Drilling process causes cracks on the surface of silver films resulting in high resistance of vias (inserted in Figure 9(c)). The high resistance vias induced leakages of the signal and produced a redundant transmission zero in the stopband. It was difficult to control the formation of cracks by drilling vias. Moreover, the slight discrepancy between the measured and simulated results is mainly from the resolution of the inkjet-printed films and the registration error of alignment process. The 


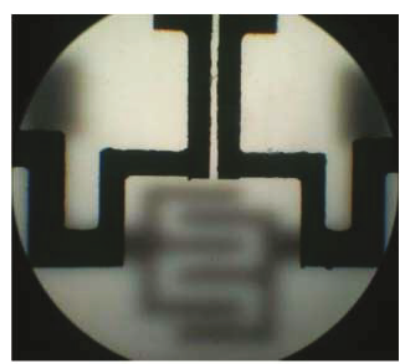

(a)

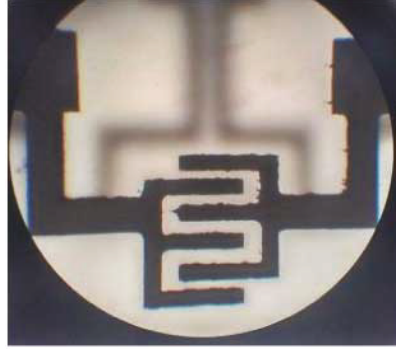

(b)

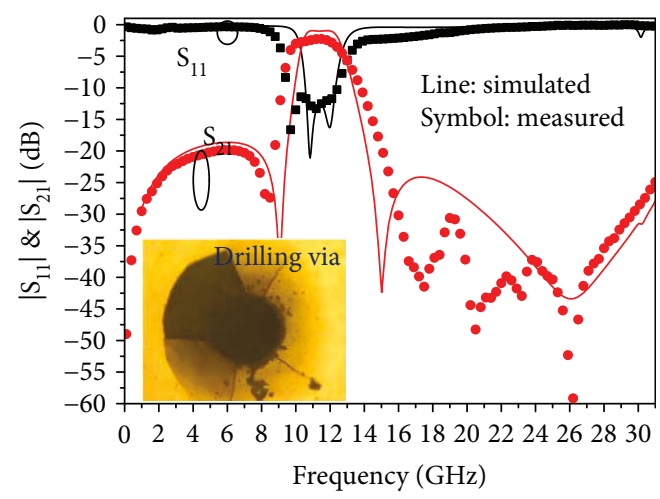

(c)

FIGURE 9: Photographs of the bandpass filter on (a) layer 1 and (b) layer 2. (c) S-parameters of the interdigital bandpass filter.

overall agreement between the simulated results and measured data was observed.

\section{Conclusions}

Inkjet-printed interdigital bandpass filter using multilayer technique on LCP substrates was successfully developed based on the insertion loss and surface morphology. The three-dimensional interdigital bandpass filter achieved a minimum insertion loss of $2.2 \mathrm{~dB}$ with a $17 \%$ bandwidth at a centered frequency of $11.5 \mathrm{GHz}$. Combining inkjet printing and multilayer LCP lamination bonding processes provides inexpensive and compact electronic components for electronic package applications.

\section{Data Availability}

The data used to support the findings of this study are available from the corresponding author upon request.

\section{Conflicts of Interest}

The authors declare that they have no conflicts of interest.

\section{Acknowledgments}

This work was partially supported by the Ministry of Science and Technology Taiwan (no. 106-2221-E-182-062) and the Chang Gung Memorial Hospital at Linkou (BMRP957).

\section{References}

[1] C.-F. Chen, T.-Y. Huang, T.-M. Shen, and R.-B. Wu, "Design of miniaturized filtering power dividers for system-in-a-package," IEEE Transactions on Components, Packaging and Manufacturing Technology, vol. 3, no. 10, pp. 1663-1672, 2013.

[2] J. C. Riou, E. Bailly, C. Bunel, L. Lenoir, and M. Pommier, "3D TSV system in package (SiP) for aerospace applications," in 2013 European Microelectronics Packaging Conference (EMPC), pp. 1-7, Grenoble, France, September 2013.

[3] J.-H. Lee, G. DeJean, S. Sarkar et al., "Highly integrated millimeter-wave passive components using 3-D LTCC system-on-package (SOP) technology," IEEE Transactions on Microwave Theory and Techniques, vol. 53, no. 6, pp. 22202229, 2005.

[4] Y. Li, L. Li, X. Dai, C. Zhu, F. Huo, and G. Dong, "Compact shorted stacked-patch antenna integrated with chip-package based on LTCC technology," International Journal of Antennas and Propagation, vol. 2014, Article ID 235847, 11 pages, 2014.

[5] L. Li, Y. Zhang, J. Wang, W. Zhao, S. Liu, and R. Xu, "Bandwidth and gain enhancement of patch antenna with stacked parasitic strips based on LTCC technology," International Journal of Antennas and Propagation, vol. 2014, Article ID 461423, 5 pages, 2014.

[6] Z.-C. Hao and J. Hong, "UWB bandpass filter with switchable notching band using multilayer LCP technology," in 2010 European Microwave Conference (EuMC), pp. 17-20, Paris, France, September 2010.

[7] E. Arabi and A. Shamin, "High Q, miniaturized LCP-based passive components, and filter design for SoP applications," in 2011 41st European Microwave Conference (EuMC), pp. 111-114, Manchester, UK, October 2011.

[8] S. Qian and J. Hong, "Miniature quasi-lumped-element wideband bandpass filter at $0.5-2-\mathrm{GHz}$ band using multilayer liquid crystal polymer technology," IEEE Transactions on Microwave Theory and Techniques, vol. 60, no. 9, pp. 2799-2807, 2012.

[9] S. Qian, Z.-C. Hao, J. Hong, J. P. Parry, and D. P. Hand, "Design and fabrication of a miniature highpass filter using multilayer LCP technology," in 2011 41st European Microwave Conference (EuMC), pp. 187-190, Manchester, UK, October 2011.

[10] K. S. Yang, S. Pinel, I. K. Kim, and J. Laskar, "Low-loss integrated-waveguide passive circuits using liquid-crystal polymer system-on-package (SOP) technology for millimeter-wave applications," IEEE Transactions on Microwave Theory and Techniques, vol. 54, no. 12, pp. 4572-4579, 2006.

[11] D. J. Chung, S. K. Bhattacharya, and J. Papapolymerou, "Low loss multilayer transitions using via technology on LCP from DC to $40 \mathrm{GHz}$," in 2009 59th Electronic Components and Technology Conference, pp. 2026-2029, San Diego, CA, USA, May 2009.

[12] H.-L. Kao, C.-S. Yeh, X. Y. Zhang et al., "Inkjet printed seriesfed two-dipole antenna comprising a balun filter on liquid crystal polymer substrate," IEEE Transactions on Components, Packaging and Manufacturing Technology, vol. 4, no. 7, pp. 1228-1236, 2014.

[13] H.-L. Kao, C.-L. Cho, and L.-C. Chang, "Inkjet-printed interdigital coupled line filter on liquid crystal polymer substrate," IEEE Electron Device Letters, vol. 34, no. 12, pp. 1584-1586, 2013. 
[14] ULTRALAM 3850, Rogers Corporation, Rogers, CT, USA, 2012, http://www.rogerscorp.com/documents/730/index.aspx.

[15] X. Y. Zhang, X. Dai, H.-L. Kao, B.-H. Wei, Z. Y. Cai, and Q. Xue, "Compact LTCC bandpass filter with wide stopband using discriminating coupling," IEEE Transactions on Components, Packaging and Manufacturing Technology, vol. 4, no. 4, pp. 656-663, 2014. 


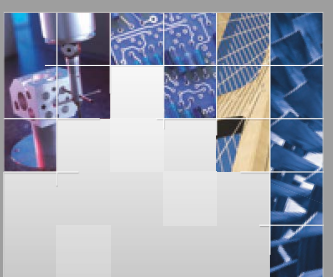

\section{Enfincering}
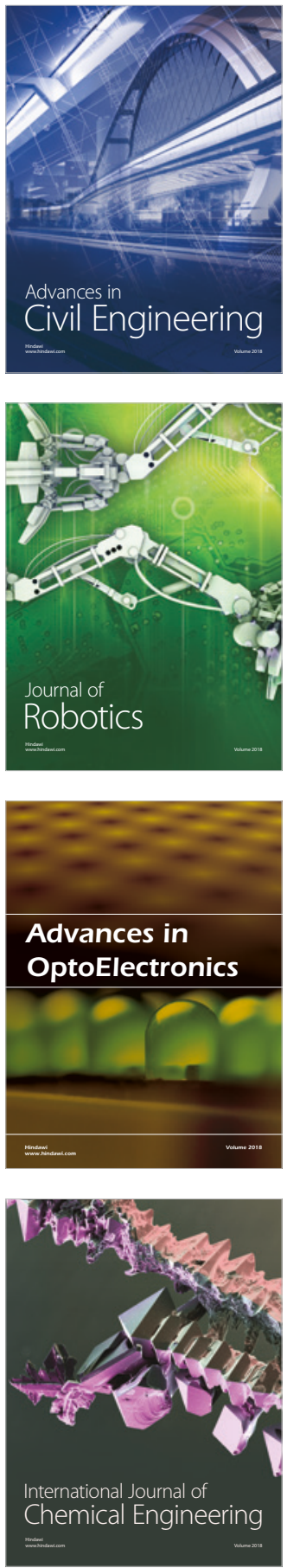

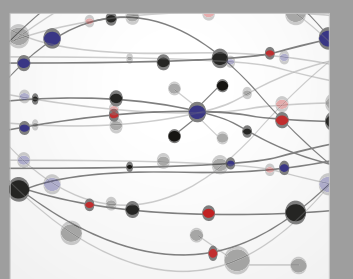

\section{Rotating \\ Machinery}

The Scientific World Journal

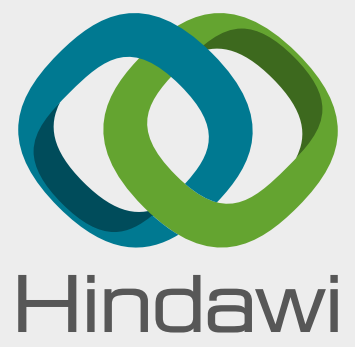

Submit your manuscripts at

www.hindawi.com
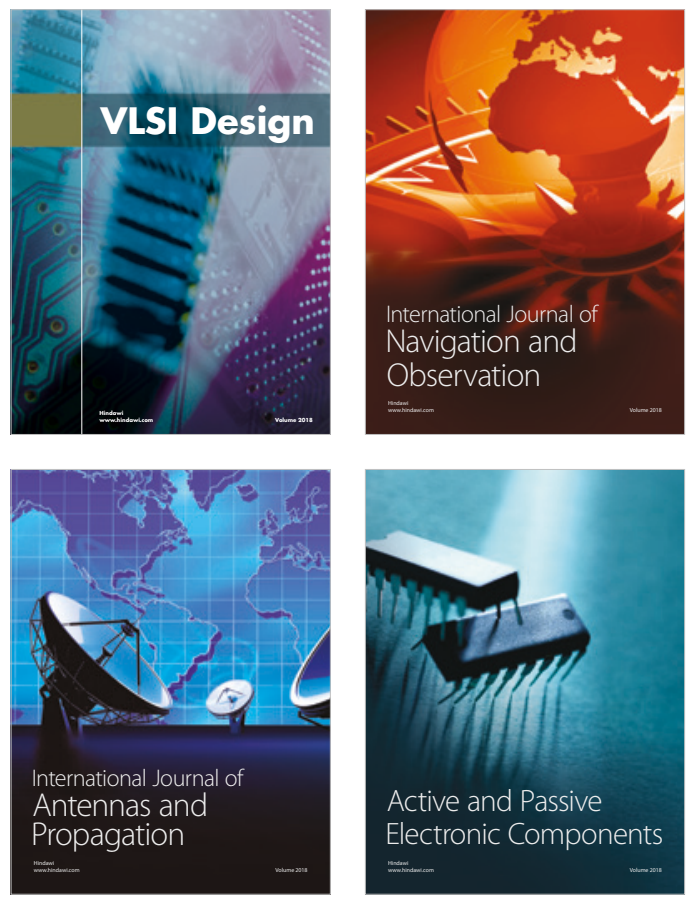
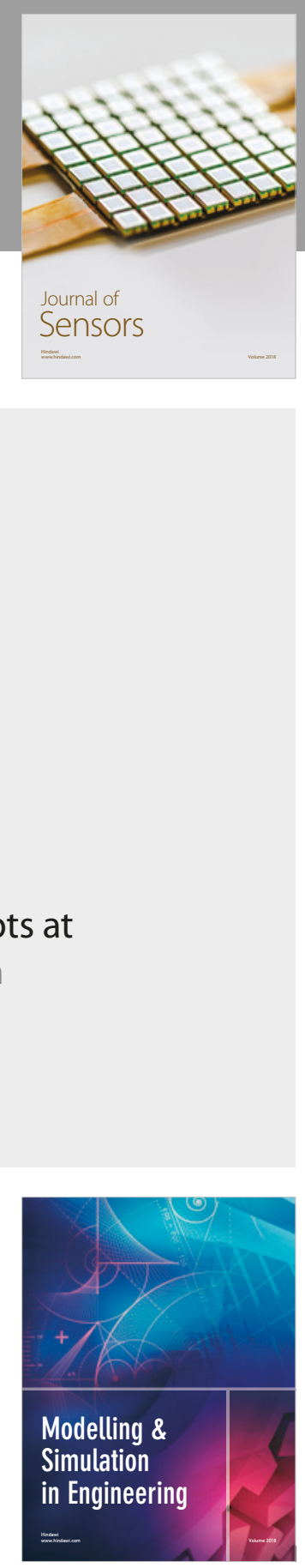

\section{Advances \\ Multimedia}
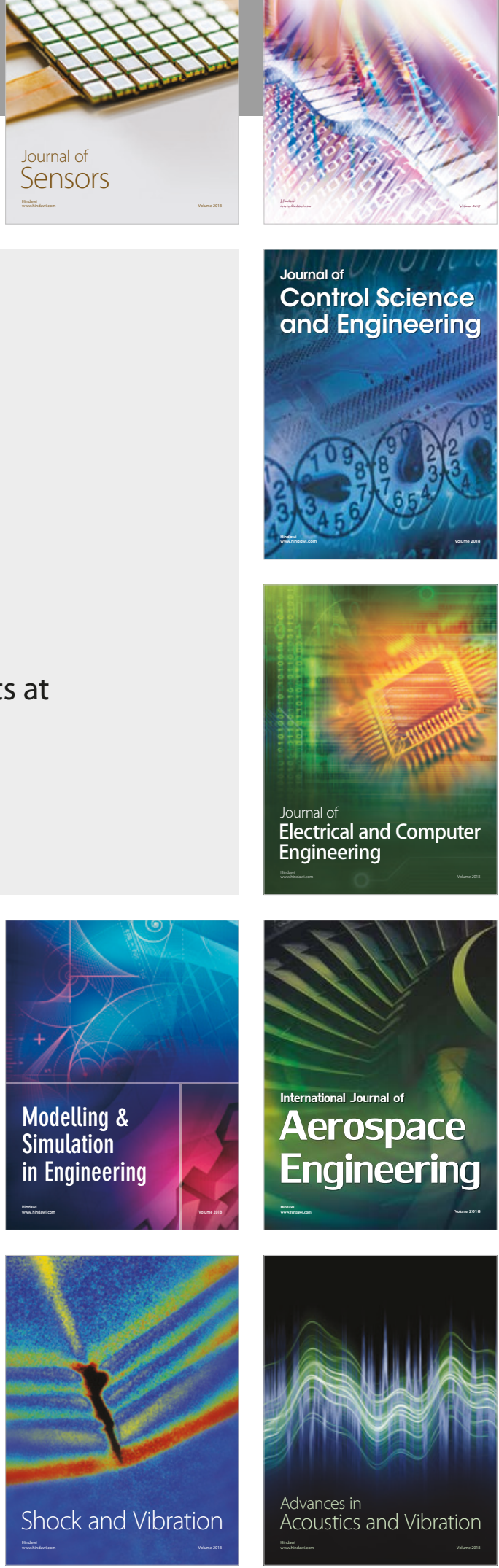